\title{
El contrabando como nuevo delito, fuente del lavado de activos en Colombia (Ley 1762 de 2015)
}

Hernando A. Hernández Quintero*

El 6 de julio de 2015, el Congreso Colombiano dictó la Ley 1762 por medio de la cual se reforma el Código Penal (Ley 599 de 2000), modificando, en forma sustancial, la regulación del delito de contrabando y erigiendo este comportamiento como delito fuente del punible de lavado de activos (art. 323 C.P.). En el presente escrito nos ocupamos de comentar los aspectos más importantes de estas modificaciones, consultando los antecedentes de estos comportamientos desviados.

\section{A. Tipificación del delito de lavado de activos en Colombia y su evolución legislativa}

Colombia, con el objeto de cumplir el compromiso adquirido en la "Convención de las Naciones Unidas Contrael Tráfico Ilícito deEstupefacientes y Sustancias sicotrópicas", suscrita en Viena el 20 de diciembre de 1988 y aprobada en nuestro país como normatividad interna por medio de la Ley 67 de 1993, tipificó el delito de lavado de activos inicialmente en el Estatuto Anticorrupción (Ley 190 de 1995), ampliando el delito de receptación que se encontraba regulado en el artículo 177 del Código Penal vigente en esa época (Decreto 100 de 1980). En esta oportunidad no se estableció en forma concreta ningún delito fuente o previo como generador de los bienes a los cuales se pretende dar apariencia de legalidad. Empero, consagró como agravante de la receptación el que dichos bienes fueran producto de los delitos de secuestro, extorsión, actividades relacionadas con el narcotráfico, operaciones de cambio o de comercio exterior o cuando se introduzcan mercancías al territorio aduanero nacional.

La inclusión del delito de lavado de activos como una forma de receptación

*Universidad Externado de Colombia.hahernandezq@hotmail.com 
generó algunas dificultades tales como la imposibilidad de aplicar el concurso de delitos entre el lavado de activos y el punible del cual provenían los recursos maculados y su ubicación como un ilícito contra la eficaz y recta impartición de justicia y no como un delito contra el orden económico social que resulta el bien jurídico protegido en estos comportamientos. Además, se advertía que la punibilidad dispuesta para sancionar ejemplarmente la perversa conducta resultaba exagerada cuando se trataba de sancionar al típico receptador.

Estas observaciones condujeron al legislador colombiano a expedir la Ley 365 de 1997, en la que se consagra el lavado de activos como un tipo penal autónomo (Art. 247 C.P./1980) y se establece en forma concreta que los bienes objeto de este comportamiento deben tener su origen mediato o inmediato en actividades de extorsión, enriquecimiento ilícito, secuestro extorsivo, rebelión o relacionados con el tráfico de drogas tóxicas, estupefacientes o sustancias sicotrópicas. De otra parte, con el objeto de sancionar penalmente a los empleados del sector financiero que, dolosamente, omitan el cumplimiento de sus obligaciones de reporte de operaciones sospechosas o de aquellas que superen una determinada cuantía, se creó el tipo penal conocido como "La omisión de control" (Art. 247 C.P./1980).

El 25 de julio del año 2001, inició su vigencia un nuevo Código Penal en Colombia, contenido en la Ley 599 del 24 de julio del año 2000. En este Estatuto, el legislador ubicó en el Título X (Delitos Contra el Orden Económico Social), el Capítulo V, al que denominó Del Lavado de Activos. Así, en el artículo 323 encontramos la figura del lavado de activos como tipo básico; en el 324 Las Circunstancias Específicas de Agravación y en el 325 la Omisión de Control.

En la descripción del delito de lavado de activos se aumentó considerablemente la lista de los delitos fuente, ubicándose dentro de ellos los siguientes: extorsión, enriquecimiento ilícito, secuestro extorsivo, rebelión, tráfico de armas, delitos contra el sistema financiero, la administración pública, o vinculados con el producto de delitos objeto de un concierto para delinquir, relacionados con el tráfico de drogas tóxicas, estupefacientes o sustancias sicotrópicas. 
La disposición comentada ha sido modificada en repetidas ocasiones para incluir nuevos delitos previos. Así, por medio de la Ley 747 de julio 19 de 2002, se incluye como delito base el tráfico de migrantes y la trata de personas. A su turno en la Ley 1121 de 2006, se establece como delito fuente del lavado de activos la financiación del terrorismo y la administración de los recursos relacionados con actividades terroristas. Más tarde, la Ley 1453 del 24 de junio de 2011, señaló como delito fuente del lavado de activos El Tráfico de Menores de Edad. Finalmente, la Ley 1762 de julio 6 de 2015, consagra como delito fuente del lavado de activos los delitos de contrabando, contrabando de hidrocarburos o sus derivados, fraude aduanero o favorecimiento y facilitación del contrabando, favorecimiento de contrabando de hidrocarburos y sus derivados, en cualquiera de sus formas ${ }^{l}$.

\section{B. EI delito de contrabando y su ubicación como delito, fuente de lavado de activos}

El contrabando, considerado como uno de los comportamientos que generan un mayor daño a la economía nacional, ha sido reconocido como delito en la legislación colombiano desde los albores de la República, llegando inclusive a contar en algún momento con su propia jurisdicción. Empero, con los vientos de la globalización y la internacionalización de la economía, nuestro país decidió en 1991 despenalizarlo y trasmutó dichos hechos punibles en contravenciones administrativas (Dcto. 1750 de 4 de julio de 1991). Pocos años después el Gobierno reconoció que la medida no había logrado los fines que se propuso y por el contrario esta conducta desviada se multiplicó y empezó a notarse su conexión con el lavado de activos ${ }^{2}$. Ante esta situación, el Congreso de la República dictó la Ley 383 del 10 de julio de 1979, con la cual se crearon los tipos penales de contrabando, favorecimiento de

\footnotetext{
${ }^{1}$ Sobre el tema se puede consultar. Hernández Quintero, HernandoA., Los delitos económicos en la actividad financiera. Séptima edición. Bogotá, Grupo Editorial Ibáñez, 2015, pp. 592 a 722. ${ }^{2}$ Hernández Q., Hernando A. y Barrero Arbeláez, Juan Manuel. El contrabando: entre el delito y la contravención. Ibagué, Ediciones Unibagué, 2016. P. 31.
} 
contrabando, defraudaciones a las rentas de aduanas y el favorecimiento por servidor público. Como consideración central para el restablecimiento del delito de contrabando se argumentó por los legisladores su relación con el narcotráfico y el lavado de activos. De esta forma, se dijo en la exposición de motivos de la Ley:

"La lucha contra el contrabando se ha convertido en uno de los más difíciles estos que ha enfrentado la actual administración. Dada la variedad de causas determinantes de dicha conducta tales como la cultura de la ilegalidad [...] el lavado de activos provenientes de actividades ilícitas, que han encontrado en el contrabando el mecanismo ilegal para introducir dineros producto del tráfico ilícito de drogas, y el hecho mismo de obtener lucro con el no pago de tributos, las medidas que se han venido adoptando definitivamente, se han quedado cortas por las limitadas posibilidades que la normatividad ofrece en la actualidad [...]".

Ante la evidente avance del contrabando en el país que, a decir de los entendidos, pueden lavar 12 billones de pesos al año ${ }^{3}$, el Gobierno Nacional impulsó una Ley en el Congreso de la República, "Por medio de la cual se adoptan instrumentos para prevenir, controlar y sancionar el contrabando, el lavado de activos y la evasión fiscal", la cual fue expedida bajo el número 1762 de julio 6 de 2015. En esta normatividad se modifica el artículo 323 del Código Penal (Ley 599 de 2000), para incluir como delitos subyacentes del lavado de activos los punibles de: Contrabando, contrabando de hidrocarburos o sus derivados, fraude aduanero o favorecimiento y facilitación del contrabando, favorecimiento de contrabando de hidrocarburos o sus derivados, en cualquiera de sus formas.

De esta forma, el tipo penal de lavado de activos en Colombia es del siguiente tenor:

"El que adquiera, resguarde, invierta, transporte, transforme, almacene, conserve, custodie o administre bienes que tengan su origen mediato o

${ }^{3}$ Diario El Tiempo, “Contrabando lava más de $\$ 12$ billones al año”. Lunes 3 de marzo de 2014, p. 7. 
inmediato en actividades de tráfico de migrantes, trata de personas, extorsión, enriquecimiento ilícito, secuestro extorsivo, rebelión, tráfico de armas, tráfico de menores de edad, financiación del terrorismo y administración de recursos relacionados con actividades terroristas, tráfico de drogas tóxicas, estupefacientes o sustancias sicotrópicas, delitos contra el sistema financiero, delitos contra la administración pública, contrabando, contrabando de hidrocarburos o sus derivados, fraude aduanero o favorecimiento y facilitación del contrabando, favorecimiento de contrabando de hidrocarburos o sus derivados, en cualquiera de sus formas, o vinculados con el producto de los delitos objeto de un concierto para delinquir o le dé a los bienes provenientes de dichas actividades apariencia de legalidad o los legalice, oculte o encubra la verdadera naturaleza, origen, ubicación, destino, movimiento o derechos sobre tales bienes, o realice cualquier otro acto para ocultar o encubrir su origen ilícito 4 incurrirá, por esa sola conducta, en prisión de diez (10) a treinta (30) años y multa de mil (1.000) a cincuenta mil (50.000) salarios mínimos legales mensuales vigentes.

La misma pena se aplicará cuando las conductas descritas en el inciso anterior se realicen sobre bienes cuya extinción de dominio haya sido declarada.

El lavado de activos será punible aun cuando las actividades de que provinieren los bienes, o los actos penados en los apartados anteriores, se hubiesen realizado, total o parcialmente, en el extranjero.

Las penas privativas de la libertad previstas en el presente Artículo se aumentarán de una tercera parte a la mitad cuando para la realización de las conductas se efectuaren operaciones de cambio o de comercio exterior, o se introdujeren mercancías al territorio nacional".

Concluimos esta colaboración afirmando que Colombia, con la inclusión del delito de contrabando como punible fuente del lavado de activos, da un importante paso en la lucha contra esta conducta desviada, de carácter transnacional, que tanto daño acarrea al orden económico social y a la moral pública.

${ }^{4} \mathrm{La}$ expresión resaltada fue declarada inexequible por la Corte Constitucional en sentencia C- 191 de 2016, M.P. Alejandro Linares Cantillo. 


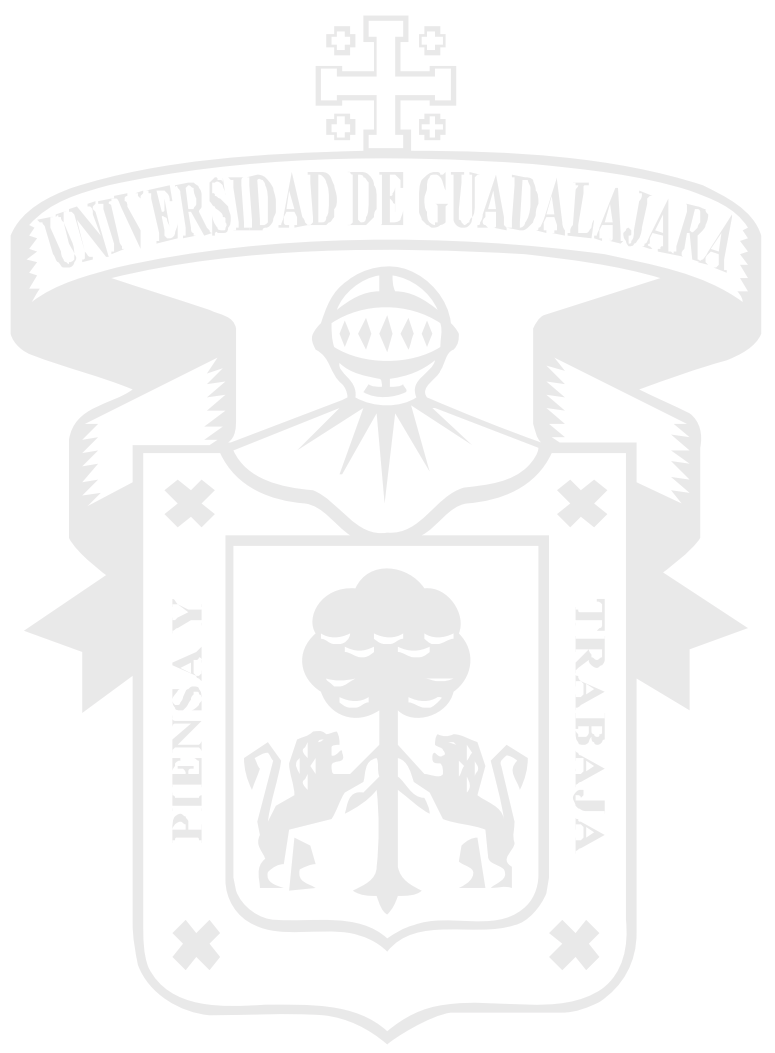

